University of Wollongong

Research Online

Faculty of Health and Behavioural Sciences -

Papers (Archive)

Faculty of Science, Medicine and Health

$1-1-2007$

\title{
The development and use of mental health triage scales in Australia
}

Marc Broadbent

Central Queensland University

Lorna Moxham

Central Queensland University, Imoxham@uow.edu.au

Trudy Dwyer

Central Queensland University

Follow this and additional works at: https://ro.uow.edu.au/hbspapers

Part of the Arts and Humanities Commons, Life Sciences Commons, Medicine and Health Sciences Commons, and the Social and Behavioral Sciences Commons

\section{Recommended Citation}

Broadbent, Marc; Moxham, Lorna; and Dwyer, Trudy: The development and use of mental health triage scales in Australia 2007, 413-421.

https://ro.uow.edu.au/hbspapers/3210

Research Online is the open access institutional repository for the University of Wollongong. For further information contact the UOW Library: research-pubs@uow.edu.au 


\title{
The development and use of mental health triage scales in Australia
}

\begin{abstract}
In Australian emergency departments, the triage of people with physical illness and injury is well developed and supported by the Australasian Triage Scale. The Australasian Triage Scale contains brief descriptors of mental illness and it is unknown if these provide the same reliability in triage decisionmaking for emergency triage nurses assessing people with a mental illness. Specialist mental health triage scales have been developed to cater for this deficit and to aid emergency staff who have lacked training in the assessment and management of people with a mental illness. A review of the development of mental health triage scales and their use in Australia identifies that using a mental health triage scale improves the competence and confidence of emergency department staff in triaging people with mental illness. Despite this, there is no consistent national approach to the emergency triage of people with a mental illness. There is ad hoc use of mental health triage scales and there are few reports of improvements in service provision to this client group as a result of the use of a mental health triage scale. These findings suggest that despite the intentions of the National Mental Health Strategy, a lack of equity remains in emergency departments in the provision of care to people with a mental illness who make up one in five of adult Australians. Consideration should be given to the introduction of a national approach to the use of a mental health triage scale in Australian emergency departments. (C) 2007 Australian College of Mental Health Nurses Inc.
\end{abstract}

\section{Keywords}

mental, scales, development, triage, health, australia

\section{Disciplines}

Arts and Humanities | Life Sciences | Medicine and Health Sciences | Social and Behavioral Sciences

\section{Publication Details}

Broadbent, M., Moxham, L. \& Dwyer, T. (2007). The development and use of mental health triage scales in Australia. International Journal of Mental Health Nursing, 16 (6), 413-421. 


\title{
Feature Article
}

\section{The development and use of mental health triage scales in Australia}

\author{
Marc Broadbent, Lorna Moxham and Trudy Dwyer \\ Faculty of Sciences, Engineering and Health, Department of Health Innovation, Central Queensland University, \\ Rockhampton, Queensland, Australia
}

\begin{abstract}
In Australian emergency departments, the triage of people with physical illness and injury is well developed and supported by the Australasian Triage Scale. The Australasian Triage Scale contains brief descriptors of mental illness and it is unknown if these provide the same reliability in triage decision-making for emergency triage nurses assessing people with a mental illness. Specialist mental health triage scales have been developed to cater for this deficit and to aid emergency staff who have lacked training in the assessment and management of people with a mental illness. A review of the development of mental health triage scales and their use in Australia identifies that using a mental health triage scale improves the competence and confidence of emergency department staff in triaging people with mental illness. Despite this, there is no consistent national approach to the emergency triage of people with a mental illness. There is ad hoc use of mental health triage scales and there are few reports of improvements in service provision to this client group as a result of the use of a mental health triage scale. These findings suggest that despite the intentions of the National Mental Health Strategy, a lack of equity remains in emergency departments in the provision of care to people with a mental illness who make up one in five of adult Australians. Consideration should be given to the introduction of a national approach to the use of a mental health triage scale in Australian emergency departments.
\end{abstract}

KEY WORDS: development, emergency, equity, mental health, triage.

\section{INTRODUCTION}

Mental health triage scales (MHTS) have been in use in Australia since 1993. This paper describes the development of MHTS and the current activity surrounding the

Correspondence: Marc Broadbent, COU Noosa, PO Box 1128 , Noosaville DC, Qld 4566, Australia. Email: m.broadbent@cqu.edu.au Marc Broadbent, RN, Cert Crit Care, Cert IV Assessment \& Workplace Training, Grad Dip Adult Ed \& Training, MEd, FCN.

Lorna Moxham, RN, MHN, PhD, MEd, BHSc, DAScNsg, Cert $\mathrm{OH} \& \mathrm{~S}$, Cert Qual Mngt, Cert IV Training \& Assessment, FACMHN

Trudy Dwyer, RN, Cert ICU, BHlthScn (Nsg), MClinEd, PhD.

Authors' contribution: Marc Broadbent - principal author; Dr Lorna

Moxham - review and contribution of content; Dr Trudy Dwyer review and contribution of content.

Accepted June 2007. assessment and management of clients with mental illness in emergency departments (EDs).

\section{BACKGROUND}

Triage is a French word derived from the verb 'trier' meaning 'to sort' (Brentnall 1997; Broadbent et al. 2004). As a process within health, it has its origins in the Napoleonic wars where Baron Dominique Jean Larrey, Napoleon's Surgeon in Chief, removed large numbers of injured soldiers from the battlefield who could potentially be salvaged to fight again and delivered them to surgical services (FitzGerald 1996). As a process within EDs, triage has been evolving since 1973 when staff at the Box Hill Hospital, Victoria, realized that there was a need to systematically sort clients presenting with more complex illness and injury. A three-tiered triage scale was 
developed to sort clients into 'urgent', 'run of the mill', and 'non-urgent'. As a result of the degree of the sophistication of clinical decision-making required by triage nursing staff at Box Hill hospital, this scale eventually evolved into a five-level scale (Brentnall 1997).

In the latter half of 1985, a triage scale was introduced into the Ipswich General Hospital, Queensland, based on the five-level scale used at Box Hill Hospital, Victoria. Similar in design and intent to the Box Hill scale, it was based on the premise that the scale 'regularized the intuitive processes used by the nursing staff in receiving patients into the department' (FitzGerald 1996; p. 205). In local testing at Ipswich Hospital, the scale was demonstrated to effectively and repeatedly describe patient populations. The scale became known as the Ipswich Triage Scale (ITS) and in testing the scale across EDs at Ipswich, Queensland and Fremantle, Western Australia, its repeatability, relevance, and outcome validity were confirmed (Jelinek 1995). In 1993, the ITS was modified slightly into the National Triage Scale (NTS), the NTS was implemented in EDs across Australia with the support of the Australasian College for Emergency Medicine (ACEM) (see Table 1).

\section{THE DEVELOPMENT OF MHTS}

As ED triage for clients with physical injury and illness was evolving as an important element of emergency care, changes to the management of people with a mental illness was imminent as Australian State and Federal Health Ministers moved to develop a strategy to improve mental health care. Originally conceived in 1992, the initial component of the strategy was the First National Mental Health Plan. This plan attempted to develop national coordination of public mental health services which before 1992 had been managed by the individual state and territory governments. The impetus for this was increasing public criticism and formal enquiries into

TABLE 1: National Triage Scale for Australasian Emergency Departments

\begin{tabular}{lll}
\hline Numeric code & Categories & Treatment acuity $\dagger$ \\
\hline 1 & Resuscitation & Immediate \\
2 & Emergency & Minutes $(<10 \mathrm{~min})$ \\
3 & Urgent & Half hour \\
4 & Semi-urgent & 1 hour \\
5 & Non-urgent & 2 hours \\
\hline
\end{tabular}

From Monash Institute of Health Services Research (2001). †Treatment acuity is defined as the maximum time to the commencement of medical treatment. mental health services around Australia (Whiteford \& Manderscheid 2002). Two principle pillars of this plan were to mainstream mental health services into general health services, to deinstitutionalize mental health care and move to a model of community-based care (Australian Health Ministers 1992). One of the effects of moving clients with mental illness out of psychiatric hospitals and care facilities and into community-based care was that more clients with increased acuity and particularly with disturbed behaviour presented to EDs where many staff were unsure of their clinical mental health needs (Stebbins \& Hardman 1993). Clients with a mental illness waiting in the ED report that they believe mental health presentations are triaged at the bottom of the list and that the ED environment is frightening and adds to feelings of agitation (Clarke et al. 2007). These reports from clients indicate that both the ED environment and the inability of the ED staff to care for them contribute to a suboptimal clinical environment.

In 1994, Smart et al. at the Royal Hobart Hospital, Tasmania, recognized that ED triage had its roots in physical injury and illness and that the NTS did not cater for people with mental illness presenting to the ED as it contained no mental health descriptors to aid its triage decision-making. This was complicated by the fact that, as part of an initial review of services, it was determined that there existed an urgent need to educate triage nurses in the assessment of clients with mental illness (Smart et al. 1999). This is consistent with the findings of Broadbent et al. (2002) who identified that the lack of confidence in nurses to assess and manage clients with a mental illness is well documented in the literature. Having implemented the NTS in January 1994, the staff in the Royal Hobart Hospital ED identified a need for mental health descriptors to be developed to aid ED nurses in the triage of clients with mental illness.

Smart et al. (1999) conducted a review of literature that identified few references to mental health triage in emergency medicine and none to do with triaging and integrating mental health problems into a general ED. The bulk of the literature that existed was from North America where the systems of assessing, treating and discharge of clients with mental illness who present to EDs are not consistent with Australian practice and therefore of little value to the problem in Australia (Smart et al. 1999).

Consequently, a study was commenced in 1994 at the Royal Hobart Hospital with the principal aim of developing a MHTS which articulated with the NTS. Other important aims were to improve nursing assessment and effectiveness of the triage of clients with a mental illness, 
to reduce waiting times, and to improve the transit times (the time from triage to departure) for clients with a mental illness (Smart et al. 1999). The initial study was completed in mid-1994, reviewed in 1996, and in 1999 having met all the study aims the results were published outlining the success of the project (Smart et al. 1999). The MHTS from the Royal Hobart Hospital is a fourtiered triage scale corresponding to categories two to five from the NTS with category one clients with mental illness sharing the same descriptors as clients with physical illness as described by the NTS (Table 2). Despite the exclusion of mental health criteria for category one clients in the Royal Hobart triage scale, the associated educational material provides the triage nurse the opportunity to make an informed assessment of the needs of the client with a mental illness. As Broadbent et al. (2004) describe, the educational material from the Royal Hobart training manual guides the triage nurse through the important components of a mental state assessment such as assessment of thought, content and process, mood and affect, perceptions, cognitive functioning, along with a discussion on common mental illnesses such as depression, suicide, anxiety, acute psychotic states, and personality disorders.

As the Royal Hobart Hospital staff were working to complete their landmark study, staff from the Area Mental Health Program within the South Eastern Sydney Area Health Service (SESAHS) were considering their response to national and New South Wales state mental health policies. These polices highlighted the need to improve the management of clients with mental health presentations to EDs. The staff of the Area Mental Health Program decided that the issue was an important one and in early 1998 agreed to develop and pilot mental health triage guidelines (Tobin et al. 1999).

Tobin et al. (1999) conducted a review of the literature and drew similar conclusions to Smart et al. (1999) about the paucity of information on mental health triage and the tendency of the international literature to represent pro- cesses that are not consistent with the Australian context. Tobin et al. (1999) were also aware of the lack of confidence and competence in managing psychiatric emergencies that was reported in the literature. Typical of the literature surrounding the capacity of ED staff to manage clients with a mental illness is a study by Bailey (1998), who found widespread negative attitudes in ED staff towards clients with a mental illness. Lack of education was said to contribute towards feelings of inadequacy and fear in dealing with this client group. This claim is supported by Brinn (2000) who determined that general nurses are not adequately prepared by their training to cope with clients who have mental illness.

Tobin et al. (1999) were critical of the existing MHTS because of the lack of differentiation between symptoms and behaviour observed by the triage nurse and behaviour reported by a third party. This was seen to be a problem for nurses not educated in the objective assessment of clients with a mental illness. Furthermore, they were concerned that existing scales used mental health terminology, thus requiring specialist knowledge by the ED triage nurse. They were also concerned by what they called inconsistent management advice. Some scales included instructions for clinical care and others did not. Where it was provided it did not distinguish between ED and mental health teams. This is not consistent with the NTS which did not concern itself with management of the client beyond the ED triage process. They concluded that none of the existing MHTS had potential for generalizability across different settings as they were 'dependent on the local culture and resources' and that there was a need to remove parochial and mental health specific language (Tobin et al. 1999; p. 12).

Following implementation and evaluation, the resulting MHTS from the SESAHS consisted of a five-tiered scale consistent with the NTS in respect of its categories and expected time to be seen. The revised five-tiered scale allowed the triage nurse to assess 'observed' and 'reported' behaviours as indicators of acuity to determine

TABLE 2: Royal Hobart Mental Health Triage Scales

\begin{tabular}{ll}
\hline Triage scale & Patient description \\
\hline $\begin{array}{l}\text { 2. Emergency } \\
\text { 3. Urgent }\end{array}$ & $\begin{array}{c}\text { Patient is violent, aggressive, or suicidal, or is a danger to self or others, or requires police escort } \\
\text { Very distressed or acutely psychotic, likely to become aggressive, may be a danger to self or others. } \\
\text { Experiencing a situational crisis }\end{array}$ \\
$\begin{array}{l}\text { 4. Semi-urgent } \\
\text { Long-standing or semi-urgent mental health disorder and/or has supporting agency/escort present } \\
\text { (e.g. community psychiatric nurse) }\end{array}$ & $\begin{array}{l}\text { Patient has long-standing or non-acute mental disorder/problem but has no supportive agency/escort. } \\
\text { May require a referral to an appropriate community resource. }\end{array}$ \\
\hline
\end{tabular}

From Smart et al. (1999). †Treatment acuity is defined as the maximum time to the commencement of medical treatment. 
a triage score without requiring specialist mental health knowledge or terminology. The scale also outlined the level of supervision required for clients within each of the categories.

Unlike the Royal Hobart MHTS that had been implemented in one ED, the SESAHS was designed for implementation across five general hospitals in the district, each with its own ED, and four mental health services, each with its own acute inpatient unit, and one communitybased mental health team (Table 3 ). This requirement for broader application of the MHTS across a number of sites meant that generalizability was an important factor in the design of the MHTS and the post-implementation report describes the successful implementation across the five sites (Tobin et al. 1999).

Thus, it emerged that by the end of 1999 there were two MHTS in use in Australia. Both MHTS had been conceived from the dominant paradigm of the conventional physical medical model of triage assessment, the concomitant lack of mental health descriptors within the NTS, and the increasing demands on EDs to assess and treat clients with mental illness.

In 2000, the ACEM altered the NTS by broadening the descriptions of presentations within each category and consequently changed its name to the Australasian Triage Scale (ATS) (Broadbent et al. 2004). The ATS was introduced across Australian EDs as the replacement for the NTS and in recognition of the omission in the NTS, included brief descriptors for mental health presentations (Table 4).

In 2001, the SESAHS MHTS was introduced into the ED of Barwon Health, Victoria (Broadbent et al. 2002). The stated goals of this project encompassed the implementation of a MHTS, a desire to strengthen consultation between ED and mental health services and to ensure a timely and effective clinical outcome for clients with a mental illness presenting to the ED. The project aimed to measure a range of changes associated with the implementation of a MHTS. A close examination of ED and mental health triage practice was undertaken to establish baseline practice and to then assess changes in practice. Data were drawn from a retrospective analysis of triage scores given to clients using only the NTS and then an analysis of triage scores given in a 3-month period following the implementation of the MHTS. Pre- and post-implementation questionnaires were used to obtain quantitative and qualitative data from the ED and mental health nurses about a range of issues including triage experience, confidence in dealing with clients with mental health issues at triage, impressions of service delivery, quality of referrals, and impact of implementing a MHTS on workload. Data were gathered that showed changes in the distribution of triage categories and these were compared with the results described by Tobin et al. (1999) as a means of demonstrating successful implementation. The Barwon Health study identified improvements in the ED triage nurses understanding of mental health assessment and positive changes in triage practice and attitude towards clients with a mental illness. Mental health triage nurses reported improvements in the ability to prioritize and organize workload. Increased and more positive collaboration, communication, and a better relationship between services were reported by both mental health and ED triage nurses (Broadbent et al. 2002).

In 2004, the Victorian Department of Human Services commissioned the National Institute of Clinical Studies (NICS) to improve the ED triage process for people presenting with a mental health problem and to improve the collaboration between EDs and mental health services (Potter \& Huckson 2006). The new mental health triage project was based on the recommendations from the Victorian Auditor General's Report on Managing Emergency Demand in Public Hospitals and the improvements to the process of mental health triage as implemented and researched at Barwon Health.

The scope of the NICS project was to develop and introduce a MHTS and provide support to 19 EDs across Victoria with education and the development of policy and procedure to manage the mental health presentations based on the triage category. This final point is important as the triage scales and the time to be seen are principal components of a successful triage process. The SESAHS MHTS as modified and adapted by Broadbent (2001) was articulated with the mental health descriptors from the ATS to create the Victorian Emergency Department Triage Tool. Anecdotal evidence suggests that, as part of a wider national programme, the MHTS developed for the Victorian NICS project has been adopted in EDs in some hospitals across Australia although specific data detailing uptake is lacking (Anonymous 2004).

\section{THE USE OF MHTS IN AUSTRALIA}

There is very little evidence in the literature to date suggesting widespread uptake of specific MHTS across Australia. While the ATS contains brief descriptors for clients with a mental illness, the need for more detailed guidelines for the triage and management of these clients has been demonstrated through improvements in staff competence and confidence and better service delivery as a result of their use (Broadbent et al. 2002; Smart et al. 1999; Tobin et al. 1999). This has served to increase 
TABLE 3: South Eastern Sydney Area Health Service Mental Health Triage Scale

\begin{tabular}{|c|c|c|c|}
\hline Triage code & Description & Treatment acuity $\dagger$ & Typical presentation \\
\hline 1 & $\begin{array}{l}\text { Definite danger to life } \\
\text { (self or others) }\end{array}$ & Immediate & $\begin{array}{l}\text { OBSERVED } \\
\text { Violent behaviour } \\
\text { Possession of weapon } \\
\text { Self-destructive behaviour in ED }\end{array}$ \\
\hline 2 & $\begin{array}{l}\text { Probable risk of danger to self } \\
\text { or others } \\
\text { - Severe behavioural disturbance }\end{array}$ & Within $10 \mathrm{~min}$ & $\begin{array}{l}\text { Extreme agitation/restlessness } \\
\text { Physically/verbally aggressive } \\
\text { Confused/unable to cooperate } \\
\text { Requires restraint } \\
\text { REPORTED } \\
\text { Attempt at self-harm/threat of self-harm } \\
\text { Threat of harm to others }\end{array}$ \\
\hline 3 & $\begin{array}{l}\text { Possible danger to self or others } \\
\text { - Moderate behaviour disturbance } \\
\text { - Severe distress }\end{array}$ & $\begin{array}{l}\text { Urgent } \\
\text { Within } 30 \mathrm{~min}\end{array}$ & $\begin{array}{l}\text { OBSERVED } \\
\text { Agitation/restlessness } \\
\text { Intrusive behaviour } \\
\text { Bizarre/disorganized behaviour } \\
\text { Confusion } \\
\text { Withdrawn and uncommunicative } \\
\text { Ambivalence about treatment } \\
\text { REPORTED } \\
\text { Suicidal ideation } \\
\text { Presence of psychotic symptoms: } \\
\text { Hallucinations } \\
\text { Delusions } \\
\text { Paranoid ideas } \\
\text { Thought disorder } \\
\text { Bizarre/agitated behaviour } \\
\text { Presence of affective disturbance: } \\
\text { Severe symptoms of depression/anxiety } \\
\text { Elevated or irritable mood }\end{array}$ \\
\hline 4 & Moderate distress & Semi-urgent within $60 \mathrm{~min}$ & $\begin{array}{l}\text { OBSERVED } \\
\text { No agitation/restlessness } \\
\text { Irritability without aggression } \\
\text { Cooperative } \\
\text { Gives coherent history } \\
\text { REPORTED } \\
\text { Symptoms of anxiety or depression without suicidal ideation }\end{array}$ \\
\hline 5 & $\begin{array}{l}\text { No danger to self or others } \\
\text { - No acute distress } \\
\text { - No behavioural disturbance }\end{array}$ & Non-urgent within $120 \mathrm{~min}$ & $\begin{array}{l}\text { OBSERVED } \\
\text { Cooperative } \\
\text { Communicative } \\
\text { Compliant with instructions } \\
\text { REPORTED } \\
\text { Known patient with chronic psychotic symptoms } \\
\text { Known patient with chronic unexplained somatic complaints } \\
\text { Request for medication } \\
\text { Minor adverse effect of medication } \\
\text { Financial/social/accommodation/relationship problems }\end{array}$ \\
\hline
\end{tabular}

Adapted from Tobin et al. (1999). †Treatment acuity is defined as the maximum time to the commencement of medical treatment.

clinical outcomes for this marginalized and stigmatized group. The number of clients with a mental illness presenting to the ED has been increasing because of the effect of mainstreaming (McDonough et al. 2004). Hundertmark (2002) states that between 1996 and 2000, the number of adult clients with mental illness presenting to the Flinders Medical Centre in South Australia rose $320 \%$ with a steady rise of $35 \%$ per year. A report on mental health presentations to EDs in Victoria found that between 1999 and 2001 there had been a 14\% increase 
TABLE 4: Mental health descriptors from the Australasian Triage Scale (ATS)

\begin{tabular}{|c|c|c|c|}
\hline ATS category & Response & Description of category/treatment acuity $\dagger$ & Clinical description \\
\hline 1 & $\begin{array}{l}\text { Immediate } \\
\text { Simultaneous assessment } \\
\quad \text { and treatment }\end{array}$ & Immediately life-threatening & $\begin{array}{l}\text { Severe behavioural disturbance with } \\
\text { immediate treat of dangerous violence }\end{array}$ \\
\hline 2 & $\begin{array}{l}\text { Assessment and treatment } \\
\text { within } 10 \mathrm{~min}\end{array}$ & $\begin{array}{l}\text { Imminently life-threatening } \\
\text { Or } \\
\text { Important time critical treatment }\end{array}$ & $\begin{array}{l}\text { Violent or aggressive } \\
\text { Immediate threat to self or others } \\
\text { Requires or has restraint } \\
\text { Severe agitation or aggression }\end{array}$ \\
\hline 3 & $\begin{array}{l}\text { Assessment and treatment } \\
\text { start within } 30 \mathrm{~min}\end{array}$ & $\begin{array}{l}\text { Potentially life-threatening } \\
\text { Or } \\
\text { Situational urgency }\end{array}$ & $\begin{array}{l}\text { Very distressed, risk of self-harm } \\
\text { Acutely psychotic or thought disordered } \\
\text { Situational crisis, deliberate self-harm } \\
\text { Agitated/withdrawn }\end{array}$ \\
\hline 4 & $\begin{array}{l}\text { Assessment and treatment } \\
\text { start within } 60 \mathrm{~min}\end{array}$ & $\begin{array}{l}\text { Potentially serious } \\
\text { Or } \\
\text { Situational urgency } \\
\text { Or } \\
\text { Significant complexity or severity }\end{array}$ & $\begin{array}{l}\text { Semi-urgent mental health problem } \\
\text { Under observation and/or no immediate } \\
\text { risk to self or others }\end{array}$ \\
\hline 5 & $\begin{array}{l}\text { Assessment and treatment } \\
\text { start within } 120 \mathrm{~min}\end{array}$ & $\begin{array}{l}\text { Less urgent } \\
\text { Or } \\
\text { Clinico-administrative problems }\end{array}$ & $\begin{array}{l}\text { Known patient with chronic symptoms } \\
\text { Social crisis, clinically well client }\end{array}$ \\
\hline
\end{tabular}

Adapted from Australasian College for Emergency Medicine (2000a). †Treatment acuity is defined as the maximum time to the commencement of medical treatment.

per year in mental health presentations to EDs. The report identifies the demand on community mental health care and the relatively low number of inpatient beds as putting increased pressure on the interface of these Victorian EDs (Department of Human Services 2006). These examples help quantify the recurring theme that is evident in the literature that EDs have been subject to increased presentations by clients with mental illness (Broadbent et al. 2002; Kalucy et al. 2005; Stuhlmiller et al. 2005; Summers \& Happell 2003; Webster \& Harrison 2004). Despite the reported increase of mental health presentations to EDs throughout Australia and the issues surrounding the management of clients with mental illness in EDs, there are only a few examples of reported use of MHTS.

King et al. (2004) identified a 10-fold increase over 10 years in clients with mental illness presenting to the Flinders Medical Centre ED. The authors found that while this client group represents less than $5 \%$ of the presentations to the ED, they account for almost $10 \%$ of the time spent in the ED by all their clients and therefore present a significant management challenge. They assert this is due to the impact of mainstreaming and draw a parallel between clients with a mental illness and drug and alcohol misuse. The authors of the paper acknowledge the lack of preparation that ED staff have had in order to deal with these clients with the focus of this study being to explore the effects of a training course aimed at improving knowledge and skills in mental health and drug and alcohol issues. In conjunction with the Flinders University School of Nursing and Midwifery, a 3-day course in emergency psychiatry and drug and alcohol issues was delivered to 40 of the 43 ED triage nurses. During the course, the MHTS from the SESAHS was introduced as a vehicle for improving the assessment of clients with mental illness as well as those with drug and alcohol problems.

The course was evaluated using a pre- and post-course self-assessment questionnaire completed by the course participants. This survey concentrated on measuring changes in the attitudes of participants to the client group and self-ratings on the improvement in skills and knowledge needed for working with this client group in the ED. No attempt was made to measure changes in the quality of care delivered from either a service or consumer perspective (King et al. 2004). The relationship between the ED and mental health service was not considered nor were changes to triage practice or responsiveness of the MHS.

In a paper describing the development of the first psychiatric emergency centre (PEC) in Australia, Frank et al. (2005) report the use of the Royal Hobart MHTS in practice. The PEC is collocated in the ED and is the first site of entry for acute psychiatric assessment (Frank et al. 
2005). The department is permanently staffed with mental health nurses, clinical nurse consultants, psychiatric registrars, and psychiatrists. The unique feature of this arrangement is that the emergency mental health service is within the ED and exists for the client group presenting to the ED. Therefore, the issue of emergency triage and referral is not as taxing as in most other centres where the mental health service is often located away from the ED. The Royal Hobart MHTS was introduced into this context in 2000 as a referral tool from ED to the PEC. Clients allocated category one by ED triage staff were sedated in the ED. All other clients in categories two to five were directed straight to the PEC where they undergo secondary triage by MH staff (Frank et al. 2005). The collocation of the PEC removes the need for ongoing management of clients by ED staff and as the ED triage is used only as an initial guide to acuity, the notion of allocating a definitive triage code that determines response times is lost in this context. The existence of an onsite PEC brings with it distinct benefits to the staff of the ED and as the paper describes, a clear advantage to clients with metal illness such as direct access to mental health professionals and short-term assessment without the need for inpatient admission (Frank et al. 2005). The report does concentrate on discussing the benefits of the PEC in terms of service delivery and does not allude to the specific benefits of using a MHTS in practice.

Happell et al. (2003) report the Royal Hobart MHTS being introduced into the ED of a large metropolitan teaching hospital in Melbourne as part of a study measuring the effectiveness of the MHTS. The focus of this study was to measure the concordance between emergency nurses and mental health nurses in applying the MHTS to clients presenting to the ED over a 3 -month period. They found a high level of discrepancy between the ED triage nurses and the mental health triage nurses in the process of triaging clients with mental health-related problems. The ED triage nurses were more likely to assign higher triage category than the mental health nurses, suggesting that they interpret common symptoms of mental health problems as more urgent. However, the ED nurses tended to assign less urgent triage categories overall to clients with mental illness compared with those with physical illness. This study found that the introduction of a MHTS alone does not create agreement between ED and mental health triage nurses and that further research needs to be done to investigate the decision-making processes of triage (Happell et al. 2003). Once again no attempt was made to measure or describe improvements in operational service delivery to clients with a mental illness.
Despite the overall improvements to practice and confidence that the introduction of a MHTS has on triage practice within the ED (Broadbent et al. 2004; Smart et al. 1999; Tobin et al. 1999), the literature surrounding the use of MHTS in Australia suggests ad hoc uptake of MHTS across Australia and a limited exploration of their use. This may be due to the fact that the ATS, with its limited mental health descriptors, was rapidly deployed into Australian EDs as a replacement for the NTS at a time when MHTS were developing a level of sophistication suitable for general ED use. ED triage nursing staff may find the use of the ATS sufficient to accurately triage clients with a mental illness and as such do not perceive the need for a specific MHTS. However, this premise has not been researched. It is necessary for the mental health component of the ATS to be tested in order to examine if used alone can it reproduce the same interrater reliability and improvements in competence and confidence in ED triage nurses that the use of an existing MHTS has demonstrated.

The ATS is a useful casemix measure and provides ability for users to measure and analyse a range of performance measures in the ED such as operational efficiency and utilization (Australasian College for Emergency Medicine 2000b). Because the Royal Hobart Hospital, the SESAHS MHTS, and the Victorian Emergency Department Triage Tool were developed to align with the triage scales existing at the time, it can be assumed that using a MHTS and the data generated from their use can be used to identify patient populations and gauge the ability of mental health triage workers to respond in a time that is consistent with the triage score as well as being consistent with the clients needs. None of the literature reviewed suggests that the ability to determine operational capacity to respond to clients with a mental illness in ED is assessed using the framework of a MHTS by either ED or mental health staff.

\section{CONCLUSION}

Specialist MHTS have evolved in response to both the increasing utilization of EDs as a point of entry for people with mental illness, and the acknowledgement that the training and ongoing education of general trained ED staff in mental health is lacking. Currently, the process for the assessment and management of clients with physical illness and injury is well established in EDs across Australia. However, the same cannot be said for clients with mental illness. There is no national approach to ED mental health triage and the reported use of MHTS in the literature does not widely describe improvements to 
service delivery. In order for clients with mental illness in the ED to receive the same level of assessment and management as clients with physical injury and illness, it is necessary to use a triage scale that incorporates mental health descriptors. For those EDs relying on the ATS as the assessment tool of choice, further work needs to be done to ensure that the mental health components of the ATS can be relied on to produce the same triage assessment outcomes for clients as achieved by the MHTS in use. Given that within a 12-month period approximately $20 \%$ of the Australian population meet the criteria for a mental illness (McGorry 2005), consideration should be given to the introduction of a national approach to the use of a MHTS in Australian EDs.

\section{REFERENCES}

Anonymous. (2004). Nurses work with NICS to bridge the emergency/mental health chasm. Australian Nursing Journal, 12, 30.

Australasian College for Emergency Medicine (2000a). Guidelines for the Implementation of the Australasian Triage Scale in Emergency Departments. [Cited 15 Dec 2006]. Available from: URL: http://www.acem.org.au/media/policies_and_ guidelines/G24_ImplementationATS.pdf

Australasian College for Emergency Medicine (2000b). Policy on the Australasian Triage Scale. [Cited 15 Dec 2006]. Available from: URL: http://www.acem.org.au/media/policies_ and_guidelines/P06_Aust_Triage_Scale_-_Nov_2000.pdf

Australian Health Ministers (1992). National Mental Health Plan. Canberra: Australian Government.

Bailey, S. (1998). An exploration of critical care nurses' and doctors' attitudes towards psychiatric patients. Australian Journal of Advanced Nursing, 15, 8-14.

Brentnall, E. (1997). A history of triage in civilian hospitals in Australia. Emergency Medicine, 9, 50-54.

Brinn, F. (2000). Patients with mental illness: General nurses' attitudes and expectations. Nursing Standard, 17, 32-36.

Broadbent, M. (2001). The Mental Health Triage Project: Final Report. Unpublished Report, Barwon Health Victoria.

Broadbent, M., Jarman, H. \& Berk, M. (2002). Improving competence in emergency mental health triage. Accident and Emergency Nursing, 10, 155-162.

Broadbent, M., Jarman, H. \& Berk, M. (2004). Emergency department mental health triage scales improve outcomes. Journal of Evaluation in Clinical Practice, 10, 57-62.

Clarke, D., Dusome, D. \& Hughes, L. (2007). Emergency department from the mental health client's perspective. International Journal of Mental Health Nursing, 16, 126131.

Department of Human Services (2006). Mental Health Presentations to the Emergency Department. Melbourne: Department of Human Services.
FitzGerald, G. (1996). The national triage scale. Emergency Medicine, 8, 205-206.

Frank, R., Fawcett, L. \& Emmerson, B. (2005). Psychiatric services: Development of Australia’s first psychiatric emergency centre. Australasian Psychiatry, 13, 266-272.

Happell, B., Summers, M. \& Pinikahana, J. (2003). Measuring the effectiveness of the national mental health triage scale in an emergency department. International Journal of Mental Health Nursing, 12, 288-294.

Hundertmark, J. (2002). The impact of mainstreaming on patient care in Australian emergency departments and liaison services. Australian and New Zealand Journal of Psychiatry, 36, 424.

Jelinek, G. (1995). Casemix classification of patients attending hospital emergency departments in Perth, Western Australia. Development and evaluation of an urgency based casemix information system for emergency departments. Doctor of Medicine Thesis, University of Western Australia.

Kalucy, R., Thomas, L. \& King, D. (2005). Changing demand for mental health services in the emergency department of a public hospital. Australian and New Zealand Journal of Psychiatry, 39, 74-82.

King, D., Kalucy, R., de Crespigny, C., Stuhlmiller, C. \& Thomas, L. (2004). Mental health and alcohol and other drug training for emergency department workers: One solution to help manage increased demand. Emergency Medicine, $16,155-161$.

McDonough, S., Wynaden, D., Finn, M., McGowan, S., Chapman, R. \& Hood, S. (2004). Emergency department mental health triage consultancy service: An evaluation of the first year of the service. Accident and Emergency Nursing, $12,31-38$.

McGorry, P. (2005). 'Every me and you': Responding to the hidden challenge of mental illness in Australia. Australasian Psychiatry, 13, 3-15.

Monash Institute of Health Services Research (2001). Consistency of Triage in Victoria's Emergency Departments. Melbourne: Department of Human Services.

Potter, R. \& Huckson, S. (2006). Victorian Emergency Department - Mental Health Triage Project. Melbourne: National Institute of Clinical Studies.

Smart, D., Pollard, C. \& Walpole, B. (1999). Mental health triage in emergency medicine. Australasian and New Zealand Journal of Psychiatry, 33, 57-66.

Stebbins, L. \& Hardman, G. (1993). A survey of psychiatric consultations at a suburban emergency room. General Hospital Psychiatry, 15, 234-242.

Stuhlmiller, C., Tolchard, B., Thomas, L., de Crespigny, C., Kalucy, R. \& Kin, D. (2005). Increasing confidence of emergency department staff in responding to mental health issues: An educational initiative. Australian Emergency Nursing Journal, 7, 9-17.

Summers, M. \& Happell, B. (2003). Patient satisfaction with psychiatric services provided by a Melbourne tertiary 
hospital emergency department. Journal of Psychiatric and Mental Health Nursing, 10, 351-360.

Tobin, M., Chen, L. \& Scott, E. (1999). Development and Implementation of Mental Health Triage Guidelines for Emergency Departments. Sydney: South Eastern Sydney Area Mental Health Service.

Webster, S. \& Harrison, L. (2004). The multidisciplinary approach to mental health crisis management: An Australian example. Journal of Psychiatric and Mental Health Nursing, 11, 21-31.

Whiteford, H. \& Manderscheid, R. (2002). Australia's national mental health strategy. British Journal of Psychiatry, 180, 210-215. 
Copyright of International Journal of Mental Health Nursing is the property of Blackwell Publishing Limited and its content may not be copied or emailed to multiple sites or posted to a listserv without the copyright holder's express written permission. However, users may print. download, or email articles for individual use. 